\title{
GESTAÇÃO NA ADOLESCÊNCIA: O OLHAR DAS ADOLESCENTES SOBRE SUA GESTAÇÃO
}

Teenage pregnancy: the look of teenagers about their pregnancy

Daiane Fernandes Felipe ${ }^{1}$, Luciane Bisognin Ceretta ${ }^{1}$, Lisiane Tuon ${ }^{1}$, Priscyla Waleska Simões ${ }^{1}$, Graziela Amboni ${ }^{1}$, Karin Martins Gomes ${ }^{1}$

1Universidade do Extremo Sul Catarinense - Criciúma

\section{Endereço para Correspondência:}

Universidade do Extremo Sul Catarinense - UNESC. Programa de Residência Multiprofissional. UNASAU. Avenida Universitária, 1105. Bairro Universitário. Criciúma - SC. CEP 88806-000. Telefone: (48) 3461 2650(48) 99842093.

Email: karin@unesc.net

Apoio Financeiro: Ministério da Saúde. Ministério da Educação. Universidade do Extremo Sul Catarinense - UNESC. 


\section{Resumo}

A adolescência é marcada pelo período em que a sexualidade está aflorada e muitos jovens iniciam a vida sexual, podendo ter como consequência a gestação inesperada. Atualmente percebe-se um aumento de adolescentes grávidas, o que torna esta questão uma preocupação para a saúde pública. Sendo assim este trabalho tem por objetivo verificar como as adolescentes veem a gravidez na adolescência. Trata-se de um estudo observacional, descritivo e com uma abordagem quantiqualitativa. Este estudo foi realizado em quatro bairros do município de Criciúma. A amostra foi censitária, totalizando 41 adolescentes na faixa etária de 13 a 19 anos que tenha vivenciado a gestação entre o período de março a setembro de 2013. A pesquisa foi realizada através de entrevista, a sua análise foi através de análise de conteúdo por categorias disponibilizadas em cinco tabelas. Mediante resultados apresentados, podemos concluir que a população predominante de nosso estudo foi composta por adolescentes com segundo grau incompleto, residentes no Município de Criciúma-SC, com renda familiar variando de $R \$ 170,00$ a $R \$ 3.000,00$, e que maioria das entrevistadas relataram possuir uma boa relação familiar com os pais, apresentando pensamentos positivos com relação a sua gestação, como também o desejo de ficar grávida.

Palavras-chave: Saúde Pública; Adolescência; Gravidez na Adolescência; Maternidade.

\section{Abstract}

Adolescence is marked by the period in which sexuality is touched on and many young people become sexually active may have the effect of unexpected pregnancy. Currently we can see an increase in teenage pregnancies, which makes this issue a concern for public health. Therefore this study aims to determine how the teens see teen pregnancy. This is an observational, descriptive and quantiqualitative approach. This study was conducted in four districts of Criciúma municipality. The sample census, a total of 41 adolescents aged 13-19 years have experienced pregnancy in the period from March to September 2013. The survey was conducted through interviews, their analysis was through content analysis categories available in four tables. By results presented, we conclude that the predominant population of our study was composed 
Artigo Original

Atenção à Saúde

of adolescents with incomplete high school, residents in the city of Criciuma-SC, with family incomes ranging from $\$ 170.00$ to $\$ 3,000.00$, and that most of respondents reported having a good family relationship with parents, have positive thoughts about your pregnancy, but also the desire to become pregnant, among other things.

Keywords: Public Health; Adolescence; Teenage Pregnancy; Maternity.

\section{INTRODUÇÃO}

A gestação na adolescência é considerada um tema contemporâneo, que passou a ser abordado por diferentes áreas do conhecimento ${ }^{1}$. Observa-se que na atualidade vem ocorrendo uma alta prevalência da gestação na adolescência, tornando-se assim um importante assunto da saúde pública ${ }^{2,3}$.

Para a Organização Mundial da Saúde (OMS), a adolescência é compreendida como o período que ocorre entre a infância e a idade adulta, e que varia dos dez aos dezenove anos ${ }^{4,5}$. Nesta fase, além das mudanças físicas impostas por esta faixa etária, ela também envolve um período de profundas mudanças psicossociais, especialmente relacionadas à maturação sexual, à formação da identidade adulta e à busca de autonomia frente aos pais 4 .

Neste período de transição da vida é que a sexualidade se aflora e que muitos adolescentes iniciam sua vida sexual. Considerando que para a saúde pública tal questão é um motivo de preocupação, pois a relação sexual pode acarretar uma gestação indesejada, o aborto e a exposição às doenças sexualmente transmissíveis ${ }^{4}$.

Um fator existente decorrente da gestação na adolescência seria a elevada taxa de evasão escolar entre mães adolescentes, no qual se mantém ainda com um quadro bastante preocupante. Tal dado é preocupante porque prejudica o futuro destas adolescentes sobre o aspecto profissional.

A gravidez na adolescência ocorre de forma bastante distinta não apenas nas diversas regiões do País, mas também nos vários grupos sociais. Apesar da gravidez na adolescência ocorrer com maior frequência nos grupos mais empobrecidos, não se pode negar que o fenômeno acontece em todos os estratos populacionais, porém suas consequências podem ser mais negativas para as adolescentes cuja inserção 
Artigo Original

Atenção à Saúde

social restringe 0 acesso a bens materiais e imateriais, como uma boa educação e valores sociais ${ }^{4}$.

Contudo é importante destacar e compreender que a gestação na adolescência não se constitui como um problema em si, mas num contexto de iniquidade que a produz e reproduz, podendo assim até fazer parte dos projetos de vida destas adolescentes, como também se revelar como elemento reorganizador de sua vida ${ }^{6}$. E por conta destes aspectos é que o presente estudo foi desenvolvido, com o objetivo de verificar como as adolescentes veem a gravidez na adolescência.

\section{METODOLOGIA}

Trata-se de um estudo observacional, descritivo e com uma abordagem quantiqualitativa. Levando em conta a quantidade da amostra e o número de vezes que apareciam determinadas categorias, este estudo não passou a ser tratado apenas como um estudo qualitativo e sim quantiqualitativo.

A população deste estudo foi composta por adolescentes entre 13 a 19 anos de idade, pautada na definição da Organização Mundial da Saúde (OMS), onde a faixa etária da adolescência varia de 10 a 19 anos. Participaram desta pesquisa o total de 41 adolescentes. Estas vivenciaram o período da gestação entre os meses de março e dezembro de 2013, além de residir em um dos quatro bairros onde foi realizada a pesquisa, pertencentes ao município de Criciúma, o qual fica localizado no Sul de Santa Catarina.

É importante destacar que a escolha dos bairros se deu por aqueles que apresentavam o nível socioeconômico entre os mais baixos do município, denominados como bairros carentes, como também pelo fato destes possuírem um alto número de adolescentes gestantes. A coleta dos dados ocorreu mediante aprovação do projeto pelo Comitê de Ética da Universidade do Extremo Sul Catarinense - UNESC, sob o protocolo 349258/2013.

Além de residirem em um dos quatro bairros determinados para a realização da pesquisa, pertencente ao município de Criciúma, as adolescentes deveriam ter realizado ou estar realizando o pré-natal na Unidade de Saúde do seu bairro, independente do mês da gestação ou do pós-parto, e assinarem o termo de consentimento livre e esclarecido assim como o termo para gravação, liberando a 


\section{Atenção à Saúde}

participação para a pesquisa, assinada pelos responsáveis ou pela mesma, quando esta possuía 18 anos ou mais.

Foram excluídas as adolescentes que não se encontravam bem, tanto física quanto emocionalmente, para realização da pesquisa, ou seja, estivesse sofrendo algum tipo de doença que dificultasse sua participação ou algum problema psíquico que a levasse a se encontrar desestruturada psicologicamente para responder as questões, como, por exemplo, um quadro de depressão.

A logística ocorreu da seguinte forma: primeiro foram selecionadas as gestantes de cada Unidade de Saúde dos bairros incluídos, em seguida foram agendadas as visitas na casa de cada gestante; as visitas foram realizadas em conjunto com as Agentes Comunitárias de Saúde, sendo que houve momentos onde foi possível realizar a pesquisa na Unidade de Saúde, quando as mesmas iriam até lá para a realização do pré-natal. No primeiro contato com a adolescente e seu responsável foram apresentados os objetivos da pesquisa e as questões éticas.

Em seguida, foi aplicado um roteiro de entrevista, composto pelas seguintes questões:

Quadro 1. Roteiro da Entrevista.

\begin{tabular}{|c|c|}
\hline Questões & Perguntas \\
\hline 01 & $\begin{array}{c}\text { Como é a relação familiar que você possuía com seus pais e irmãos, } \\
\text { antes e depois da gestação? }\end{array}$ \\
\hline 02 & Se você pudesse voltar atrás, evitaria esta gestação? Por quê? \\
\hline 03 & Como você vê ou sente essa gestação? \\
\hline 04 & O que este filho significa para você? \\
\hline
\end{tabular}

Após a realização de todas as entrevistas, as falas foram transcritas e as respostas foram agrupadas para a realização da análise de conteúdo, que designa o tratamento de dados qualitativos e que vem a promover a análise de categorias, sendo que as categorias serão apresentadas em tabelas ${ }^{7}$.

Comparando-se a pesquisa qualitativa, à abordagem quantitativa, podemos entender que cada um dos dois tipos de método possui o seu papel, lugar e adequação. Considerando que ambos podem gerar resultados importantes sobre a realidade social ${ }^{7}$. 
É importante destacar que, com o intuito de manter o sigilo quanto à identidade dos sujeitos da pesquisa, o processo de apresentação e discussão dos dados das entrevistadas ocorrerá da seguinte forma: para as adolescentes que ainda não haviam ganhado: Gestante 1 (G.1), Gestante 2 (G.2), Gestante 3 (G.3), assim por diante; e para aquelas que já haviam ganhado o bebê: Puérpera 1 (P.1), Puérpera 2 (P.2) e Puérpera 3 (P.3), para que assim já fosse possível visualizar nas falas das adolescentes quais delas já havia ou não ganhado a criança.

\section{RESULTADOS E DISCUSSÃO}

A pesquisa foi realizada com 41 adolescentes residentes em quatro bairros do município de Criciúma, com renda familiar variando de $R \$ 170,00$ a $R \$ 3.000,00$, e média de $R \$ 1.393,55$ ( $\pm 796,61)$. Com relação à condição de moradia, $26,8 \%(n=11)$ das adolescentes possuíam casa própria, o restante morava com os pais ou com os sogros.

Como podemos observar na tabela 1, 63,5\% ( $n=26)$ possuem 16 a 18 anos de idade. Com relação aos anos de estudo, o mesmo mostrou-se variável, pois 51,3\% $(n=21)$ apresentaram de 10 a 13 anos de estudo, sendo que a maioria estava começando o ensino médio.

Da amostra, 34 adolescentes haviam parado de estudar, e 32 ainda não haviam completado o ensino médio, sendo que 11 destas adolescentes já se encontravam trabalhando.

$\mathrm{Na}$ tabela 1 ainda podemos observar o tempo de gestação em que se encontravam as adolescentes, considerando que 31,7\% ( $n=13)$ das entrevistadas já haviam ganhado a criança, e as outras ainda encontravam-se no período da gestação entre o segundo e o nono mês.

Para melhor visualização, levando em conta o número da população pesquisada, as categorias de cada questão serão apresentadas em tabelas juntamente com a frequência em que foram respondidas e o percentual obtido. É importante destacar que a maioria das adolescentes relatou mais de uma categoria por questão. Havendo entrevistadas que apresentaram até quatro categorias numa mesma resposta. 
Tabela 1. Características da população estudada.

\begin{tabular}{ll}
\hline Variável & $\mathbf{n}(\%)$ \\
\hline Idade da adolescente & $07(17,0)$ \\
\hline 13 a 15 & $26(63,5)$ \\
16 a 18 & $08(19,5)$ \\
19 & \\
\hline Anos de estudo das adolescentes & $20(48,7)$ \\
\hline 06 a 09 anos & $21(51,3)$ \\
10 a 13 anos & $12(29,2)$ \\
\hline Tempo de gestação da adolescente & $08(19,5)$ \\
\hline 02 a 04 meses & $07(17,2)$ \\
05 a 07 meses & $13(31,7)$ \\
08 a 09 meses & $1(2,4)$ \\
\hline Já ganhou & \\
Dado não informado & \\
\hline
\end{tabular}

Tabela 2. Relação Familiar.

\begin{tabular}{lr}
\hline A relação familiar antes da gestação & $\mathbf{n} \%$ \\
\hline Relação familiar sempre foi boa e/ou normal & $26(53,1)$ \\
Reduz a relação familiar apenas na figura da mãe & $08(16,3)$ \\
Como se dava o seu relacionamento com os irmãos & $07(14,2)$ \\
Possuía um relacionamento familiar distante ou ruim & $05(10,2)$ \\
Relato de abandono pela figura da mãe ou do pai & $03(06,2)$ \\
Total & $\mathbf{4 9}(\mathbf{1 0 0})$ \\
\hline A relação familiar depois da gestação & \\
\hline Relata dificuldade de comunicação com os pais & $08(38,1)$ \\
A relação familiar melhorou & $07(33,3)$ \\
Possui uma relação distante com os irmãos & $03(14,3)$ \\
Ainda possui um relacionamento familiar distante & $03(14,3)$ \\
Total & $\mathbf{2 1}(\mathbf{1 0 0 )}$
\end{tabular}

Desta forma, a tabela 2 é referente à seguinte questão: Como era a relação familiar que você possuía com seus pais e irmãos, antes e depois da gestação? Antes 
da gestação a categoria que apresentou maior porcentagem foi a Relação familiar, sempre foi boa e/ou normal de acordo com 26 (53,1\%) adolescentes entrevistadas e apenas 05 (10,2\%) consideravam sua relação familiar distante ou ruim. Depois da gestação, 07 (33,3\%) adolescentes colocaram que a relação familiar com seus pais melhorou, porém algumas ainda expressaram a dificuldade de comunicação com os pais $08(38,1 \%)$.

Neste estudo foi possível observar que a maioria das adolescentes relatou que a relação familiar antes da gestação era boa, como nas falas a seguir: "Uma relação... Boa, me dou bem com a minha família toda (P.5, 15 anos)". "Boa, a gente conversava bastante, boa (G.12, 18 anos)". Havendo poucos casos onde as meninas relataram as seguintes falas: "Era meio conturbada, não conseguia conversar com eles, não tinha muito contato assim, é, não éramos muito ligados e sempre foi assim (G.18, 18 anos)". "Antes era mais difícil, era complicado o negócio com os meus pais, era uma briga, eu e minha mãe discutíamos direto, agora é mais ou menos, mas não é tudo aquilo (P. 34, 17 anos)".

O cuidado dos vínculos construídos no interior das famílias se tornou uma preocupação cada vez mais presente para diferentes profissionais, isto por causa da força que esses laços possuem para o desenvolvimento de crianças e adolescentes ${ }^{8}$. Neste sentido, pode-se relacionar ao fato que estas adolescentes estarão construindo uma família, tendo como base de referência o vínculo que ela possuía com sua família de origem, ou seja, seus pais.

A família é vista como o espaço de extrema importância, onde toda criança tem o direito de nascer e crescer em situação de proteção, segurança, afeto e cuidados, para tanto é preciso compreender que o tema família pode envolver vivências carregadas de significados, representações, opiniões ou experiências das mais diversas situações e nelas podem ser incluídas as lembranças boas e as ruins, como também afetos e desafetos, perdas, entre tantos outros componentes que, no conjunto, escreve a história de vida de cada indivíduo ${ }^{9}$.

Desta forma, é importante destacar que a representação familiar já não é mais aquela constituída apenas pela figura do pai, da mãe e dos filhos, pois é possível encontrar casos onde a criança é criada pelos avôs, pelos tios, ou até mesmos pelos irmãos mais velhos, como podemos observar nas falas de algumas adolescentes: "Meus avôs é que ficavam comigo, vivi mais com eles, e a minha relação com eles era 
Artigo Original

Atenção à Saúde

ótima, boa, bem boa, não sentia falta da minha mãe, pelo fato de eu não conviver com ela eu não sentia, nem saudade eu sentia (G.25, 19 anos)". "É que eu morava como meu irmão, meu pai faleceu quando eu tinha nove anos e a minha mãe estava presa (G.30, 19 anos)".

Esta questão de representação familiar também nos leva a categoria onde as adolescentes reduziam a relação familiar apenas na figura da mãe, como podemos observar nas falas seguintes: "Morava com a minha mãe, era só eu e ela, sempre foi normal, boa (G.2, 17 anos)". "Eu não morei com meu pai, mas foi boa assim, a gente sempre teve uma relação bem boa eu e a minha mãe (G.16, 19 anos)".

Nestes casos é possível observar o modelo familiar monoparental, sendo que normalmente estes casos são chefiados pela figura da mãe, na qual esta assume um papel de autoridade e se responsabiliza por toda a organização do cotidiano familiar, exercendo, portanto, tarefas que vão desde o cuidado do filho e da casa até o sustento financeiro da família ${ }^{8}$.

O fato é que o modelo familiar que estas adolescentes possuem, de alguma maneira pode influenciar no modelo familiar que elas buscam construir agora, principalmente com a vinda deste filho, podendo até mesmo assumir o modelo familiar monoparental, levando em conta a forma como foi criada e o meio onde está vivendo como base do que ela deseja para seu futuro e o significado que este filho tem na sua vida.

Desta forma, na tabela 3 é possível visualizar as categorias da segunda questão, que seria: Se você pudesse voltar atrás evitaria esta gestação? Por quê? 19 $(46,3 \%)$ adolescentes colocaram que sim, que evitariam esta gestação, já $17(41,5 \%)$ colocaram que não e $05(12,2 \%)$ se mostraram indecisas em relação à pergunta. Desta forma, a tabela foi subdividida para melhor compreensão.

Para as meninas que colocaram não para essa questão um dos principais motivos foi o fato de ver essa gestação como a realização de um sonho, como podemos visualizar na tabela 3 , houve $08(36,3 \%)$ adolescentes que colocaram esta resposta, sendo que $05(22,7 \%)$ declararam que queriam ficar grávidas; outra categoria que se destacou foi aquela em que elas consideraram esta gestação algo bom e que the fez bem, de acordo com 05 (22,7\%) adolescentes. 
Tabela 3. Evitaria a gestação: sim ou não.

\begin{tabular}{lr}
\hline Não evitaria por que & $\mathbf{n} \%$ \\
\hline Vê essa gestação como a realização de um sonho & $08(36,3)$ \\
Considera essa gestação algo bom, que lhe fez bem & $05(22,7)$ \\
Queria ficar grávida & $05(22,7)$ \\
Porque já possuí amor pela criança & $02(09,0)$ \\
Não sabe definir um porquê, apenas expressa que não evitaria & $02(09,0)$ \\
Total & $\mathbf{2 2 ( 1 0 0 )}$ \\
\hline Evitaria por que & \\
\hline Associa a sua gestação a uma série de consequências & $12(48,0)$ \\
Que este não é o momento certo, que deveria ser mais para a frente & $08(32,0)$ \\
Não sabe definir um porquê, apenas afirma que evitaria & $03(12,0)$ \\
Não me arrependi de ficar grávida, mas evitaria & $02(08,0)$ \\
Total & $\mathbf{2 5 ( 1 0 0 )}$ \\
\hline
\end{tabular}

Para as meninas que viam esta gestação como a realização de um sonho, é possível observar um desejo claro de assumir o papel de ser mãe e de ter um filho, sem ao menos pensar nas consequências que isso poderia trazer na sua vida: "Sempre quis, chegava até a chorar quando vinha pra mim (G.11, 14 anos)". "Eu tinha o sonho de ser mãe, pedi muito pra Deus me dar um filho e Deus me deu (P.24, 19 anos)". "Porque é meu sonho ter um neném, sim, não foi planejado, mas eu o queria muito (G.35, 18 anos)". Esta última fala também se encaixa na categoria "Queria ficar grávida", sendo que nesta categoria também podemos destacar as seguintes falas: "Porque eu queria e ele também (G.15, 13 anos)". "Porque eu queria, já queria antes de engravidar (P.19, 18 anos)".

Nestes relatos podemos considerar a seguinte hipótese: já que há um grande desejo que ocorra uma gestação, por mais conhecimentos que elas poderiam ter sobre os métodos contraceptivos, isso não iria evitar sua gravidez. E isto pode estar ligado à concepção que esta adolescente tem sobre a gestação, o fato de assumir um novo papel como a de mãe e o de formar uma família, como também a sensação de que este bebê é seu e somente seu, tornando-se assim um ser há tempo desejado, ainda mais vivendo em um meio cultural e num ambiente aonde ter um filho na sua idade é natural. 
Neste estudo, foi possível observar que para estas adolescentes a maternidade corrobora com uma descrição em que é vista como algo inimaginável, e que só é possível compreendê-la quem a vivencia, desta forma faz com que a gravidez seja constituída, como uma dádiva, um sonho a ser alcançado, algo que distingue quem tem e quem não tem, quem é e quem não é mãe ${ }^{10}$. E sendo assim, é possível compreender que em um meio cultural onde a maternidade carrega este sinônimo de maneira tão forte o desejo de ter um filho passa a ser normal mesmo na adolescência.

Corroborando com esta pesquisa, um estudo realizado nos EUA com adolescentes entre 14 e 19 anos demonstrou que entre as meninas que relatavam o desejo de engravidar havia a ocorrência da gestação num período de 18 meses, ainda mais se estas jovens já haviam abandonado a escola ${ }^{11}$. Desta forma, é possível observar que quando o desejo de ter um filho já se mostra eminente para as adolescentes pode ser impossível evitar a sua ocorrência.

A categoria na qual a adolescente considerava a gestação como algo bom e que Ihe fazia bem apresentou os seguintes relatos: "Ela foi a melhor coisa que aconteceu na minha vida (G.30, 19 anos)". "Porque parece que ela rejuvenesce a gente, a vê crescer, vê cada sorriso, sabe? Só de imaginar como vai ser o primeiro passinho assim, eu não teria evitado (P.32, 17 anos)".

Entre as adolescentes que colocaram que "sim, evitariam essa gestação", é importante destacar as seguintes categorias: as que associam a sua gestação a uma série de consequências, conforme expressado por 12 (48,0\%) entrevistadas, e a categoria composta por $08(32,0 \%)$ adolescentes em que compreendem que este não seria o momento certo para ficar grávida, ou seja, que a vinda deste filho deveria ser mais para a frente.

Sendo que na primeira categoria mencionada acima encontramos as seguintes falas: "Porque não precisaria parar de estudar, eu estaria trabalhando, e ele (marido) comprou um apartamento agora e eu poderia estar ajudando ele (G.2, 17 anos)". "Claro que queria ficar grávida, mas agora evitava, porque filho dá muito prejuízo (G.4, 15 anos)". "Evitaria, apesar de estar feliz com meu filho, vai ser... Vai ser uma responsabilidade... Uma responsabilidade que por um erro eu vou carregar para o resto da vida (G.12, 18 anos)". "Essa gestação evitaria, a primeira não, porque dois filhos agora com dezesseis anos é muito ruim (G.40, 16 anos)". 
Como podemos observar, algumas destas jovens já estão vivenciando as possíveis consequências da gestação na adolescência, como o fato de ter que parar de estudar por causa da gravidez. Sendo que há estudos que mostram que por causa desta situação muitas adolescentes acabam abandonando a escola ${ }^{12}$. E ao levar em conta a situação socioeconômica destas adolescentes, que na maioria não é favorável, justifica-se o fato de verem a vinda deste filho como um prejuízo.

Com relação à responsabilidade, a maternidade tende a funcionar como mecanismo quase automático que gera mais responsabilidade a esta adolescente, como também mais aumento sobre as restrições relacionadas à disponibilidade do seu próprio tempo ${ }^{13}$. Mas apesar da adolescente estar feliz com a vinda deste filho, algumas conseguem compreender a dimensão da sua responsabilidade sobre os cuidados que devem assumir com a criança, e por ser tão nova e ter que abrir mão de tantas coisas, algumas destas adolescentes passam a ver este filho como um erro; no entanto foi possível observar que nem todas as adolescentes se sentiram assim, já que para a maioria a gestação foi algo desejado.

É importante destacar que algumas das entrevistadas já se encontravam na segunda gestação, corroborando com estudos que indicam que muitas dessas adolescentes acabam voltando a ficar grávida logo no primeiro ano após a primeira gestação ${ }^{14}$.

A tabela 4 é composta pela seguinte questão: Como você vê ou sente essa gestação? A maioria das adolescentes apresentou a seguinte categoria: Sensações de bem estar e felicidade sobre a gestação, com total de 29 (59,1\%). Outra categoria foi "sentimento de ansiedade para com a vinda da criança", conforme apresentado por $06(12,2 \%)$ adolescentes. No entanto, outras $06(12,2 \%)$ não souberam responder esta questão.

"Motivo de alegria (G.09, 18 anos)". "Nossa foi bem bom, ai eu amei ficar grávida (P.19, 18 anos)". "Felicidade, várias coisas boas (G.27, 16 anos)". "Ah uma sensação maravilhosa, no sentir ele se mexer e tudo (P.28, 17 anos)".

Tais sentimentos de alguma forma podem estar ligados com 0 desenvolvimento da maternidade e pelo desejo de serem mães, ainda mais se recebem o apoio da família. A descoberta da gravidez proporciona diversos tipos de emoções, como alegria, surpresa e, algumas vezes, medo. Os fatores como o 
Artigo Original

Atenção à Saúde

planejamento pessoal e, principalmente, o desejo da mulher em relação à gestação, contribuem para o predomínio da vivência de sentimentos positivos ${ }^{15}$.

Tabela 4. Os sentimentos envolvidos na gestação destas adolescentes.

\begin{tabular}{ll}
\hline Como a adolescente sentia a sua gestação & $\mathbf{n} \%$ \\
\hline Sensações de bem estar e felicidade sobre a gestação & $29(59,1)$ \\
Ansiedade e desejo pela da vinda da criança & $06(12,2)$ \\
Não soube responder & $06(12,2)$ \\
Sentimento de amadurecimento e responsabilidade & $03(06,1)$ \\
Sentimentos de medo com relação ao parto & $03(06,1)$ \\
Sensações de angústia & $02(04,0)$ \\
Total & $\mathbf{4 9 ( 1 0 0 )}$ \\
\hline
\end{tabular}

Sobre os sentimentos de ansiedade surgiram falas como: "Muito feliz, acho que amadureci muito também é... Aí não sei a gente não vejo à hora de ganhar, de ver o rostinho, de saber o sexo (G.12, 18 anos)". "Não vejo à hora de sair, é boa, só que é ansiedade demais, eu quero que nasça de uma vez (G.13, 18 anos)". "É boa, mas uma das coisas que incomoda é a pressão, agora no final vai me dando um nervoso (G.23, 16 anos)".

A adolescente, ao engravidar, passa a conviver naquele momento com dois eventos estressores, que ocorrem simultaneamente: a fase da adolescência e a gestação ${ }^{16,17}$. Considerando o fato que no terceiro trimestre ocorre um aumento no nível de ansiedade nas mulheres por causa da aproximação do parto ${ }^{18}$. E essa situação não seria diferente para estas adolescentes, ainda mais levando em conta suas expectativas com relação à criança.

A tabela 5 está ligada a última questão: O que este filho significa para você?. $30(65,2 \%)$ das adolescentes afirmaram que este filho significa tudo para ela, e como podemos observar foi a categoria que apresentou maior porcentagem, outra categoria foi que este filho significa felicidade e motivo de alegria para elas, com $07(15,4 \%)$ das entrevistadas. 
Tabela 5. O significado deste filho para a adolescente.

\begin{tabular}{lr}
\hline Para a adolescente, o que significa deste filho na vida delas & $\mathbf{n} \%$ \\
\hline Este filho é tudo & $30(65,2)$ \\
Felicidade, alegria e a realização de um sonho & $07(15,4)$ \\
Amor (recebo e dou amor) & $05(10,8)$ \\
Não soube responder & $04(08,6)$ \\
Total & $\mathbf{4 6}(\mathbf{1 0 0 )}$ \\
\hline
\end{tabular}

Sobre a primeira categoria é possível destacar as seguintes falas: "Agora ela é tudo na minha vida, não tenho mais nada, tudo (P.6, 17 anos)". "Tudo, motivo de alegria, amor, o que eu não tive da minha mãe eu vou dar pra ele, tudo (G.9, 18 anos)". "Ai hoje pra mim é tudo, muita gente diz: Você fala demais nesse teu filho e se tu chegar a perder? Mas eu não vou perder. Se não for problema de saúde, vai ser meu pro resto da vida (G.12, 18 anos)". "Ah tudo... Ah se eu não tivesse o meu filho eu não seria nada, mas agora que eu estou vendo que ele precisa de mim e eu preciso dele, então pra mim ele é tudo (P.21, 16 anos)". "Ai tudo, nossa foi até bom quando o primeiro veio... Agora este segundo aconteceu, mas olha não tem explicação, tudo que a gente fica triste e preocupada, têm eles pra... Pra consolar nós, e quem diz que é ruim é mentira... É dizem que é ruim ter filho, que passa trabalho, sei lá, depende da pessoa que passa trabalho, porque eu não passei (G.36, 19 anos)".

Através das falas, percebe-se o apego dessas adolescentes ao filho, para elas é algo tão bom que as consequências da gestação, antes mencionadas, agora passam despercebidas. Como se este filho the trouxesse novas esperanças e the desse algum tipo de estabilidade e conforto.

A busca pela estabilidade e permanência, que se revela através da percepção deste filho como uma propriedade, assim poderia se traduzir numa tentativa de obter autonomia e atingir a maturidade, sobre a percepção da própria competência em dar conta das tarefas da casa e dos cuidados do bebê ${ }^{19}$. Pode-se observar que este filho possui um significado muito importante na vida destas adolescentes, podendo promover uma mudança de vida, podendo trazer esperança e novo significado de vida, e mesmo nesta fase da vida ele não chega a ser considerado como algo ruim. 


\section{CONCLUSÕES}

A população deste estudo foi composta por 28 adolescentes grávidas e mais 13 que haviam recentemente ganhado a criança, com idades entre 13 a 19 anos, e o segundo grau incompleto, residentes de quatro bairros localizados no Município de Criciúma-SC, com renda familiar variando de $R \$ 170,00$ a $R \$ 3.000,00$. O total da amostra foi de 41 entrevistadas.

É importante destacar que o objetivo deste estudo foi alcançado. O resultado desta pesquisa demonstrou que apesar de algumas das adolescentes já estarem sofrendo algumas das consequências previstas após a gestação, ao mesmo tempo elas se encontravam felizes com a chegada do bebê, e até mesmo sonhavam com isso, com o fato de ser mãe e acabam por ver essa gestação como algo bom e que Ihe fez bem.

Estes resultados sugerem que existem diferentes vivências da maternidade e que, para um grupo de jovens mães adolescentes, a maternidade é uma experiência de vida plena, cheia de significados positivos. Nesta amostra podemos levar em consideração os aspectos culturais, como o fato de ser tão comum ficar grávida na adolescência no bairro onde a jovem mora e que pode influenciar este desejo de ter um filho, levando em conta que a maioria relatou um significado positivo sobre a chegada deste filho em sua vida.

A gestação na adolescência é uma questão de saúde pública que gera muita preocupação na sociedade, pela perspectiva de futuro destas adolescentes e de seus filhos, como também por conta das consequências da gestação na adolescência. Porém fica cada vez mais difícil ver uma solução para resolver este problema, pois como foi observado neste estudo, pode-se dizer que a gestação foi, em sua maioria, planejada pelas adolescentes.

Para a maioria das adolescentes entrevistadas, a gestação fazia parte do seu projeto de vida. Levando em considerações estes dados, uma hipótese para a prevenção da gravidez na adolescência seria acompanhar, orientar e conhecer o projeto de vida destas adolescentes, mostrando novos caminhos, possibilidades de tornar outros sonhos realidade, apesar das dificuldades socioeconômicas que possuem. 


\section{REFERÊNCIAS}

1. Ferreira RA, Ferriani MdGC, Mello DFd, Carvalho IPd, Cano MA, Oliveira LAd. Análise espacial da vulnerabilidade social da gravidez na adolescência. Cad saúde pública. 2012;28:313-23.

2. Martinez EZ, Roza DL, Guimarães MCG, Bava C, Achcar JA, Dal-Fabbro AL. Gravidez na adolescência e características socioeconômicas dos municípios do Estado de São Paulo, Brasil: análise espacial. Cad saúde pública. 2011;27(5):855-67.

3. Moni SA, Nair MKC, Devi RS. Pregnancy among unmarried adolescents and young adults. J Obstet Gynaecol India. 2013;63(1):49-54.

4. Cerqueira-Santos E, Paludo SdS, Schirò EDB, Koller SH. Gravidez na adolescência: análise contextual de risco e proteção. Psicol estud. 2010;15:72-85.

5. Santos JO, Silva CFdS, Petenão E, Soster FCB, Berard MB, Silva SR. Perfil das adolescentes com reincidência de gravidez assistidas no setor público de Indaiatuba (SP). J Health Sci Inst. 2009;27(2):115-21.

6. Harris MB, Allgood JG. Adolescent pregnancy prevention: Choosing an effective program that fits. Child youth serv rev. 2009;31(12):1314-20.

7. Minayo MCS. O desafio do conhecimento. Pesquisa qualitativa em saúde. 8 ed: Editora Hucitec; 2008.

8. Silva ML, Polli RG, Sobrosa GMR, Arpini DM, Dias ACG. Da normatização à compreensão: caminhos construídos para a intervenção familiar. Mudanças. 2012;20(1-2):13-21.

9. Nery MA. A convivência familiar e comunitária é direito da criança e do adolescente e uma realidade a ser repensada pela escola. Cad CEDES. 2010;30(81):189-207.

10. Hoga LAK, Borges ALV, Reberte LM. Razões e reflexos da gravidez na adolescência: narrativas dos membros da família. Esc Anna Nery Rev Enferm. 2010;14(1):151-7.

11. Sipsma HL, Ickovics JR, Lewis JB, Ethier KA, Kershaw TS. Adolescent pregnancy desire and pregnancy incidence. Women's health issues : official publication of the Jacobs Institute of Women's Health. 2011;21(2):110-6.

12. Ferraro AA, Cardoso VC, Barbosa AP, Silva AAM, Faria CA, Ribeiro VS, et al. Childbearing in adolescence: intergenerational dejà-vu? Evidence from a Brazilian birth cohort. BMC pregnancy childbirth. 2013;13(1):1-8.

13. Moreira RLCA, Rasera EF. Maternidades: os repertórios interpretativos utilizados para descrevê-las. Psicol soc. 2010;22(3):529-37. 
14. Esteves JR, Menandro PRM. Trajetórias de vida: repercussões da maternidade adolescente na biografia de mulheres que viveram tal experiência. Estud psicol. 2005;10(3):363-70.

15. Leite MG, Rodrigues DP, Sousa AAS, Melo LPT, Fialho AVM. Sentimentos advindos da maternidade: revelações de um grupo de gestantes. Psicol estud. 2014;19(1):115-24.

16. Santosa SR, Schor N. Vivências da maternidade na adolescência precoce. Rev Saude Publica. 2003;37(1):15-23.

17. Schwartz T, Vieira R, Geib LTC. Apoio social a gestantes adolescentes: desvelando percepções. Ciênc saúde coletiva. 2011;16(5):2575-85.

18. Oliveira EFV, Gama SGN, Silva CMFP. Gravidez na adolescência e outros fatores de risco para mortalidade fetal e infantil no Município do Rio de Janeiro, Brasil. Cad saúde pública. 2010;26(3):567-78.

19. Silva AAA, Coutinho IC, Katz L, Souza ASR. Fatores associados à recorrência da gravidez na adolescência em uma maternidade escola: estudo caso-controle. Cad saúde pública. 2013;29(3):496-506. 